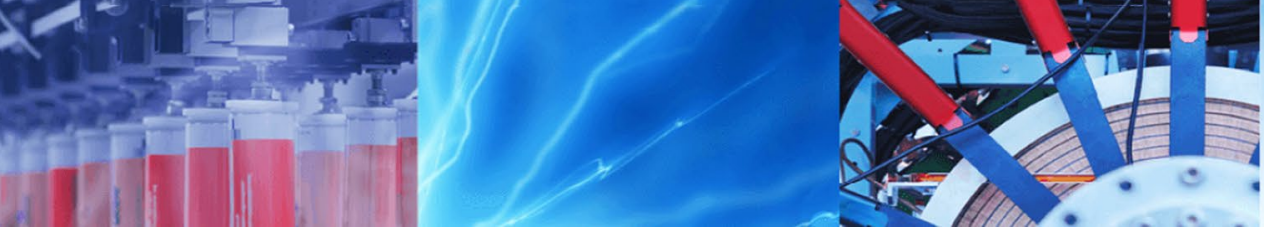

Research Article

\title{
An experimental investigation of dynamic elastic moduli and acoustic velocities in heterogeneous carbonate oil reservoirs
}

\author{
Ali Shakouri $^{1}$ - Oveis Farzay ${ }^{1}$ (D) ${\text { Mohsen } \text { Masihi }^{2} \text { - M. H. Ghazanfari }}^{2}$ - A. M. Al-Ajmi ${ }^{3}$
}

(c) Springer Nature Switzerland AG 2019

\begin{abstract}
One of the most common methods for determining elastic moduli of rocks is the acoustic velocity log. The elastic moduli of reservoir rocks are widely used in geomechanical modeling, borehole stability analysis, and hydraulic fracture design. In the carbonate reservoirs, the effect of the fluid type on the dynamic elastic modulus under high pressure conditions have rarely been investigated. Carbonate oil reservoirs are known for their heterogeneity and anisotropic nature. Therefore, it is a challenge to find a reliable correlation between the acoustic velocity and rock/fluid properties. In this paper, the acoustic velocities of several carbonate samples with a wide range of porosity and permeability from different oil reservoirs were measured under different confining and axial stresses. Our study shows that wettability of rock samples plays an important role in the acoustic velocities, particularly in tight pores. In addition, an increase in compressional velocity after saturation was reported. In order to fully understand the effect of fluid type, a new parameter [relative change of shear modulus (RCS)] is defined. Experimental results shows that strong water wet samples have higher RCS values rather than oil wet samples which means that the wettability of the carbonate rocks is one of the main important factors in dynamic elastic modulus.
\end{abstract}

Keywords Acoustic velocity $\cdot$ Carbonate reservoirs $\cdot$ Dynamic elastic moduli $\cdot$ Wettability $\cdot$ Triaxial test

\section{List of symbols}

UCS Uniaxial compressive strength

$\sigma \quad$ Principal stress

E Young's modulus

$\mathrm{K} \quad$ Bulk modulus

$\mu \quad$ Shear modulus

$\checkmark \quad$ Poisson's ratio

Vp Compressional velocity

Vs Shear velocity

RCS Relative change of shear modulus

\section{Introduction}

Carbonate reservoirs are known for their complexity in lithology, heterogeneity of the rock properties and the presence of fractures, which complicate their geomechanical studies. At the same time, more than $50 \%$ of oil production worldwide comes from carbonate reservoirs that form nearly $60 \%$ of oil reserves, especially in the Middle East. In the exploration phase for carbonate reserves, seismic studied playing a significant role in understanding the earth system of the fields. The seismic exploration uses both compressional and shear acoustic waves to define and map reservoir bound-aries, and to detect the available hydrocarbons in the fields. In the oil industry, the acoustic waves are preferably used to determine the mechanical properties of the oil formations due to their economic

Oveis Farzay, Farzay.ov@ppars.com | ${ }^{1}$ Department of Petroleum Engineering, Petropars LTD, Tehran, Iran. ${ }^{2}$ Department of Petroleum and Chemical Engineering, Sharif University of Technology, Tehran, Iran. ${ }^{3}$ Department of Petroleum and Chemical Engineering, Sultan Qaboos University, Muscat, Oman. 
feasibility, short test time needed and the non-destructive nature of the tests.

The rock properties obtained from the application of acoustic velocities are called dynamic rock elastic moduli. These dynamic elastic properties should be then converted to the conventional static rock elastic properties in which an empirical relation is usually utilized $[3,9,10$, $12,16,21,25]$. The static rock elastic moduli are used to determine the formation strength parameters (UCS, friction angle, tensile strength), in situ stresses magnitudes, well completion design, reservoir subsidence modelling, borehole stability, wellbore breakouts characterization, fracture pressure prediction, anisotropy parameters and building a geomechanical model $[11,15,17,18,35,36]$. Even though it should be mentioned that for some rocks like flint [2], shear velocity showed no or poor correlation with their mechanical properties like UCS.

The compressional velocity $\left(\mathrm{V}_{\mathrm{p}}\right)$ and shear velocity $\left(\mathrm{V}_{\mathrm{s}}\right)$ depend on the rock elastic modulus and density and are given by:

$v_{p}=\sqrt{\frac{K+\frac{4}{3} \mu}{\rho}}$,

$\mathrm{V}_{\mathrm{s}}=\sqrt{\frac{\mu}{\rho}}$,

where $\mathrm{K}$ is bulk modulus, $\mu$ is the shear modulus and $\rho$ is bulk density. If a rock is isotropic and linearly elastic then one can correlate the velocities and moduli through the following equations [26]:

$E_{d}=\rho \frac{V_{p}^{2}(1+\vartheta)(1-2 \vartheta)}{(1-\vartheta)}$

$\vartheta_{d}=\frac{0.5-\left(\frac{v_{s}}{v_{p}}\right)^{2}}{1-\left(\frac{v_{s}}{v_{p}}\right)^{2}}$

$\mathrm{K}_{\mathrm{d}}=\rho\left(\mathrm{V}_{\mathrm{p}}^{2}-\frac{4}{3} \mathrm{~V}_{\mathrm{s}}^{2}\right)$

$\mu_{\mathrm{d}}=\rho \mathrm{V}^{2}$,

where $E$ is Young's modulus, $\mathrm{U}$ is Poisson's ratio and the subscript $d$ represents the dynamic elastic property of the module.

There are many studies have been conducted to establish a correlation between the acoustic waves and porosity $[19,23,29]$. In this regard, carbonate rocks were covered in several studies and the measurements for the shear and compressional velocities were reported to understand the phenomena $[1,3,5,27,28]$. The studies conducted in carbonate rocks showed that the acoustic velocities have an inverse relationship with porosity and density and the mineral influence on the velocities are negligible.

After fluid substitution, the shear modulus has been reported to remain constant [1]. This is only valid for low frequency range, and for high frequency acoustic waves (i.e., ultrasonic frequency) the dispersion in velocity may take place and violate Gassmann's rule which is given by

$\mathrm{K}_{\mathrm{sat}}=\mathrm{K}_{\mathrm{dry}}+\Delta \mathrm{K}$

$\mu_{\mathrm{dry}}=\mu_{\text {wet }}$

Based on Eqs. (7) and (8), after sample saturation, the bulk modulus will increase while the shear modulus will remain constant. The increase of the bulk modulus will depend on the porosity, existing minerals and pore fluid compressibility. Gassmann's works were based on the assumption that there is no interaction between fluid and rock. However, the rock-fluid interaction and velocity dispersion mechanisms may cause shear velocity and shear modulus changes which stated as shear weakening and shear strengthening if shear modulus decreases and increases, respectively $[1,6,7,20,31]$.

At a high frequency range greater than $0.5 \mathrm{MHz}$, two major mechanisms contribute to velocity changes, namely, the global flow and local flow. Global flow is based on dragging of fluid on solid due to acoustic waves. For the local flow, it is activated during pore space deformation in which the pore fluid is forced to move into less compliant pores and cracks depending upon the applied stresses, permeability and fluid viscosity [20,34]. Accordingly, fluid substitution as one of the controlling factors in acoustic velocity may either increase or decrease the compressional velocity and decrease the shear velocity. This is due to an increase in the bulk density and bulk modulus while the shear modulus remains constant during the saturation process, as per Gassmann's rule. It should be highlighted that the shear velocity may also increases or decreases like the compressional velocity provided that shear weakening or shear strengthening take place, according to Eqs. (1) and (2).

Many studies have been conducted in order to build a correlation between acoustic velocities and elastic modulus. Most of these studies were conducted in sandstones samples and few towards analyzing carbonate samples. Due to the high heterogeneity and the presence of the cracks in carbonate samples, the interpretation of the acoustic velocities becomes complex which results in limiting the work in carbonate formations. Some of the important researches on the carbonates and sandstones are listed below. 
Rafavich et al. [27], measured the acoustic velocity of 96 carbonate plugs with different mineralogy, lithology, and porosities at a frequency of $1 \mathrm{MHz}$ and a confining stress of 10,000 psi. Samples were tested on both dry and brined saturated conditions. Their results showed that porosity and density are the main factors controlling acoustic velocities, and the lithology and mineralogy influences are negligible.

Anselmetti and Eberli [5], measured the shear and compressional velocities of 210 carbonate samples with different sedimentology and age under a confining stress of $100 \mathrm{MPa}$. They observed that the porosity is the main factor controlling the shear and compressional velocities. They also found out that the mineralogy and depositional age have no major impact on acoustic velocities.

Khazanehdari and Sothcott [20], investigated acoustic velocities on sandstones in sonic and ultrasonic frequency range. They observed that samples saturated with brine and crude oil or kerosene, generally show a decrease and increase in shear modulus, respectively. They attributed these changes to rock softening and hardening mechanisms and velocity dispersion such as local flow. Their research also indicated that these mechanisms are more active at low effective stress as open fracture and low aspect ratio pores have a high surface area for rockfluid interaction. Fluid viscosity also affects the acoustic velocity and generally increases it due to viscous coupling mechanism.

Baechle et al. [7], showed that during saturation of samples with water, shear modulus might increase or decrease resulting in shear strengthen or shear weakening respectively. They claimed that water rock interaction at the grain contacts and velocity dispersion are the main causes of these changes.

Fortin et al. [17], measured acoustic velocities of several mounted transducers on sandstone samples in several directions and locations in order to measure anisotropy parameters. They used a triaxial cell to apply pore pressure by introducing distilled water and introduced the axial and confining stresses in the range of 60-100 MPa. They monitored velocity changes, axial and radial strains, and porosity reduction during pressurization. After that, Fortin and co-workers used the seismic velocities and acoustic emissions from their study to analyze the compaction bands in sandstone formations.

Adam et al. [1], measured 9 carbonate samples at different frequency range for the seismic waves (i.e., $3-3000 \mathrm{kHz}$ ) and applied ultrasonic waves with $0.8 \mathrm{MHz}$ under different effective stresses up to $31 \mathrm{MPa}$. They observed that during saturation of the samples with water, shear modulus decreases as a result of rock frame weakening.
Ameen et al. [3], derived a general exponential correlation between the rock mechanical properties, formation strength and porosity for carbonate samples. Their studies also revealed the effect of rock lithology and pore type on acoustic waves. They derived correlations between static and dynamic elastic modulus under confining stress up to 6000 psi.

Najibi et al. [25], measured acoustic velocity in two carbonate reservoir in Iran in a dry condition at atmospheric pressure and derived correlations between dynamic and static Young's modulus. Their studies also predicted the static Young's modulus and the uniaxial compressive strength (UCS) from compressional velocity.

Wang et al. [32], made 4 synthetic carbonates with high porosity and high permeability and measured acoustic velocities with two pore fluids, that is, brine and kerosene, which have different contact angle (i.e., oil wet and water wet). They observed that wettability also affects acoustic velocity and the wetting phase reduced shear velocity and shear modulus due to an expected molecular slipping between fluid and solid.

In all of the previous works, the effect of confining stress, effective stress, porosity, permeability, and density have been extensively investigated. However, to simulate the real reservoir conditions, the studied sample should be under a triaxial stress state during the tests to give more realistic results for a field. In this study, besides applying the confining and pore pressures to the samples, an axial stress representing one of the horizontal stresses of a field was applied. In the tested samples, the applied confining stress represents the vertical stress and another horizontal stress of the field. This test setup gives a special in situ stress condition where the vertical stress and one of the horizontal stresses are equal and representing the intermediate and minimum principal stresses (i.e., $\sigma_{2}=\sigma_{3}$ ); and the other horizontal stress represents the major principal stress $\left(\sigma_{1}\right)$. The main aim of this study is to investigate the effect of the axial stress besides the confining stress on acoustic waves and elastic moduli in dry and wet conditions using brine and dead oil in carbonate samples. In addition, the wettability effects on these parameters are examined.

\section{Materials and methods}

The studied carbonate samples were collected from several carbonate reservoirs in Iran. At first, all of the 16 carbonate samples were cleaned using soxhlet apparatus with toluene and methanol for 12-15 h. After the cleaning process, the samples were dried in an oven at $110^{\circ} \mathrm{C}$ for 10-12 h. The dimensions and weight of all the samples were measured and their densities were calculated 
accordingly. For porosity measurements, the vacuum condition was applied for $10 \mathrm{~h}$. Then, the samples were saturated with water and the saturated weights were measured. The diameter of all the tested samples was $38.1 \mathrm{~mm}$. Permeability was measured using core flooding instrument with single phase fluid (i.e., water) under confining pressure of $1000 \mathrm{psi}$ and two flow rates of 0.5 and $1 \mathrm{cc} / \mathrm{min}$.

Shear and compressional velocities were measured under both dry and wet conditions using brine and dead oil. The applied center frequency in the measurements was $0.5 \mathrm{MHz}$ using the pulse transmission technique developed by Birch [8], as shown in Fig. 1. The schematics of the instrument is shown in Fig. 1. In the tests, a digital oscilloscope was used for measuring the shear and compressional travel time. The experimental system was calibrated with two aluminum and plastic plugs of different lengths. As it can be seen in Fig. 1, the core holder was horizontally positioned. Thus only the horizontal plugs were selected and the confining pressure represents the vertical stress. The effect of pore structure on the testing results could not be neglected [13] however it was not covered in this study. The selected plugs were CT-Scanned and the plugs without Visual pores, Vugs, and Stylolite were selected for the next procedure.

For the dry tests, the measurements were conducted after a drying process in the oven for the samples and applying a vacuum condition over few days. The applied confining stress increased gradually up to 6000 psi. For the measurement of acoustic time travel at different confining stress levels, the applied stress was hold for few minutes to stabilize the pressure and reach an equilibrium condition. In addition, in the conducted dry tests, the axial stress was also applied up to 5000 psi.

For the study of wet conditions, the samples were saturated with a fluid (i.e., brine or dead oil) and placed in a desiccator. In the tests, the axial and confining stresses were increased and then the pore pressure was applied. The pore pressure value was kept lower than the axial and confining stresses by at least $100 \mathrm{psi}$. For brine preparation, distilled water and sodium chloride with concentration of 150,000 ppm (15\%) were used. Dead oil viscosity was measured using a rotational viscometer. The pore fluid properties are summarized in Table 1. For the wettability measurement the most common method, that is, contact angle, was adopted. The determined properties of the carbonate samples are recorded in Table 2.

Table 1 Pore fluid properties

\begin{tabular}{lll}
\hline Property & Brine & Dead oil \\
\hline Density $\left(\mathrm{g} / \mathrm{cm}^{3}\right)$ & 1.11 & 0.96 \\
Viscosity $(\mathrm{cp})$ & 1 & 130 \\
\hline
\end{tabular}
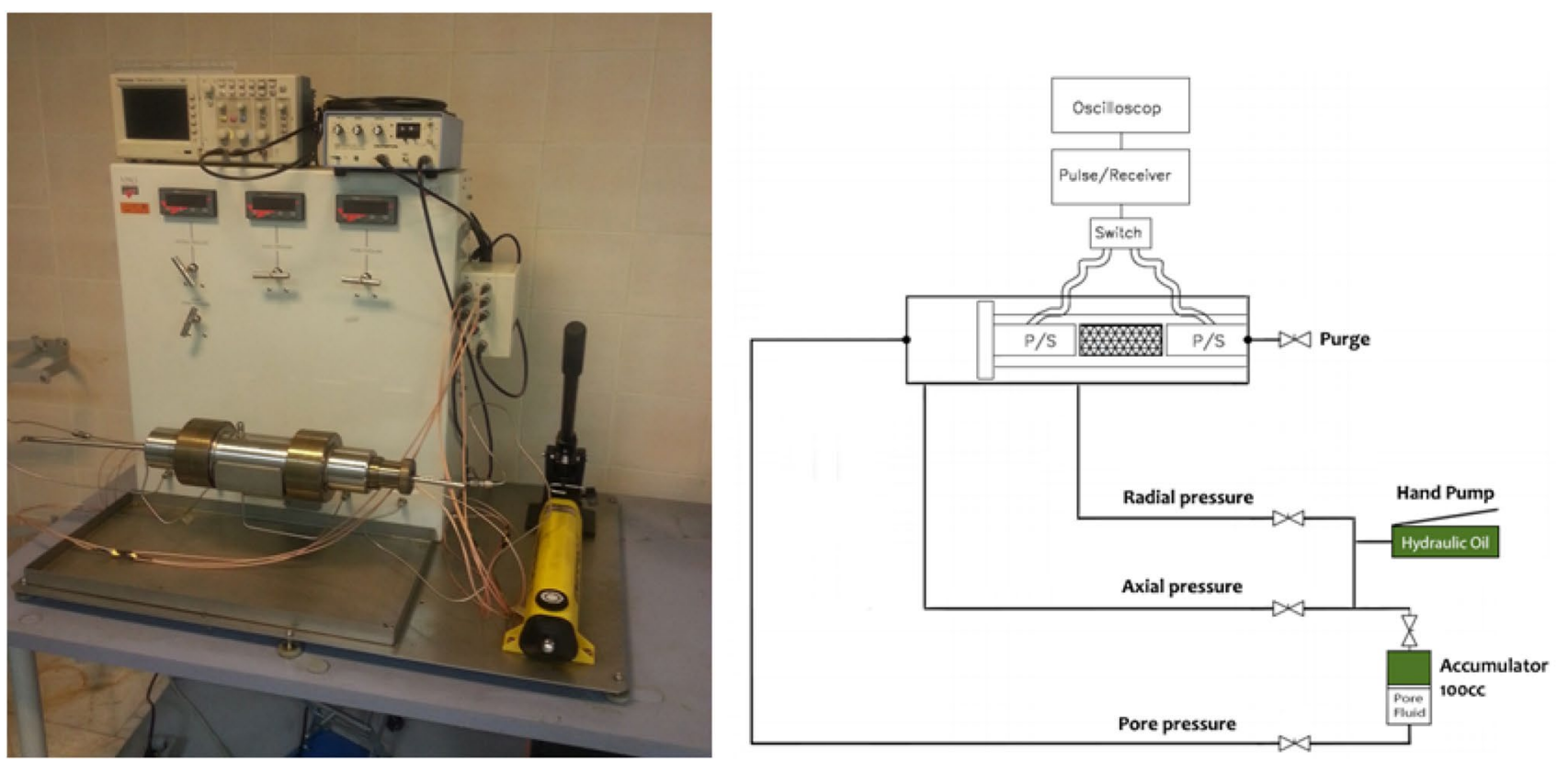

Fig. 1 Experimental and schematic of the acoustic velocity measurement set up 
Table 2 The studied carbonate samples properties

\begin{tabular}{lllllll}
\hline Sample & Density $\left(\mathrm{g} / \mathrm{cm}^{3}\right)$ & Porosity $(\%)$ & $\begin{array}{l}\text { Permeability } \\
(\mathrm{md})\end{array}$ & $\mathrm{Vp}(\mathrm{m} / \mathrm{s})$ & Vs $(\mathrm{m} / \mathrm{s})$ & $\begin{array}{l}\text { Contact } \\
\text { angle } \\
\left({ }^{\circ}\right)\end{array}$ \\
\hline A1 & 2.3043 & 15.89 & 11 & 4800 & 2989.16 & 0 \\
A2 & 2.3443 & 15.63 & 2 & 4745.56 & 2711.29 & 60 \\
A3 & 2.6338 & 1.45 & 0.03 & 5136.36 & 3280.64 & 95 \\
A4 & 2.4533 & 11.93 & 0.32 & 5453.731 & 3277.13 & 45 \\
A5 & 2.3166 & 3.66 & 0.26 & 5353.53 & 3227.77 & 96 \\
A6 & 2.5661 & 4.9 & 0.05 & 5916.6 & 3191.94 & 72 \\
A7 & 2.8100 & 2.12 & 0.035 & 6080.487 & 3473.75 & 91 \\
A8 & 2.3445 & 14.675 & 5.3 & 5000 & 2914.389 & 68.2 \\
A9 & 2.3418 & 15.23 & 6.5 & 3396.22 & 1935.48 & 0 \\
A10 & 2.1491 & 19.62 & 0.03 & 4856.73 & 2733.225 & 42 \\
A11 & 2.4952 & 3.53 & 4.5 & 5084.07 & 3113.82 & 75 \\
A12 & 2.2018 & 16.96 & 7 & 4575.229 & 2891.01 & 0 \\
A13 & 2.1987 & 9.98 & 0.25 & 2394.573 & 1605.5 & 0 \\
A14 & 2.5769 & 1.83 & 0.03 & 3930.821 & 2125.5 & 65 \\
A15 & 2.3818 & 10.33 & 1.44 & 2446.103 & 1644.978 & 42 \\
A16 & 2.6736 & 3.46 & 0.03 & 5450.420 & 2872.45 & 52 \\
\hline
\end{tabular}

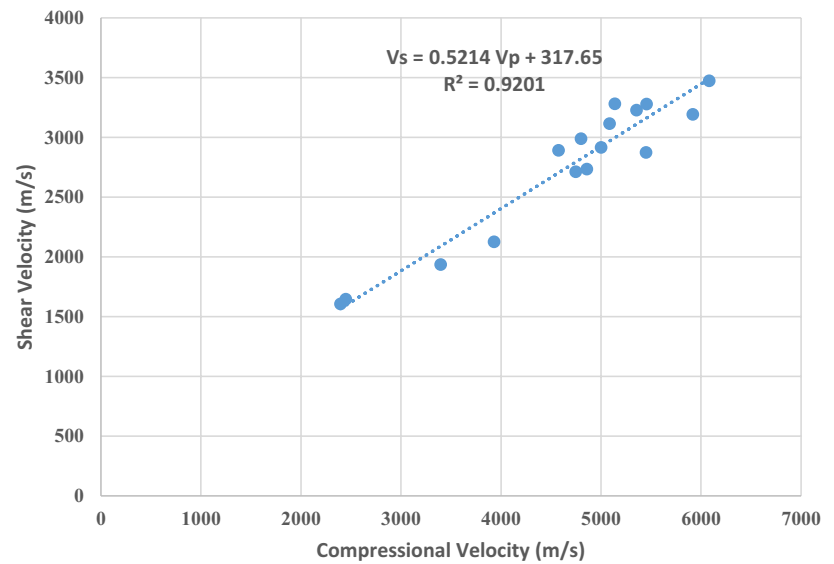

Fig. 2 The relation between the shear and compressional velocities under dry conditions with no application of stresses

\section{Results and discussion}

\subsection{Compressional and shear velocity relation}

Under dry conditions with no application of stresses, the results of the measurements show that the compressional and shear velocities can be correlated linearly with $R^{2}=0.921$ (see Fig. 2). The determined equation for the acoustic velocities from the analysis is given by

$\mathrm{V}_{\mathrm{s}}=0.5214 \mathrm{~V}_{\mathrm{p}}+317.65$,

After applying a confining stress of 6000 psi and an axial stress of 5000, the fitting goodness for the relation

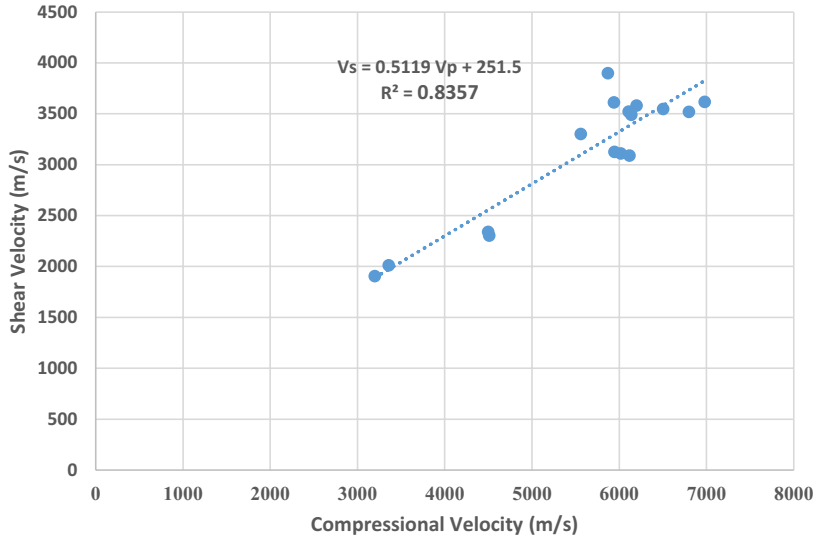

Fig. 3 The relation between the acoustic velocities under axial and confining pressure

between the acoustic velocities decreased to $R^{2}=0.8357$, as shown in Fig. 3. For this case, the equation for estimating shear wave velocities from compressional velocities is expressed by

$\mathrm{V}_{\mathrm{s}}=0.5119 \mathrm{~V}_{\mathrm{p}}+251.5$,

The changes of the coefficients in the determined equations of the acoustic velocities [i.e., Eqs. (9) and (10)] could be attributed to the pore structure complexity of the carbonate reservoirs, as pointed out previously by Verwer and co-workers [31]. 


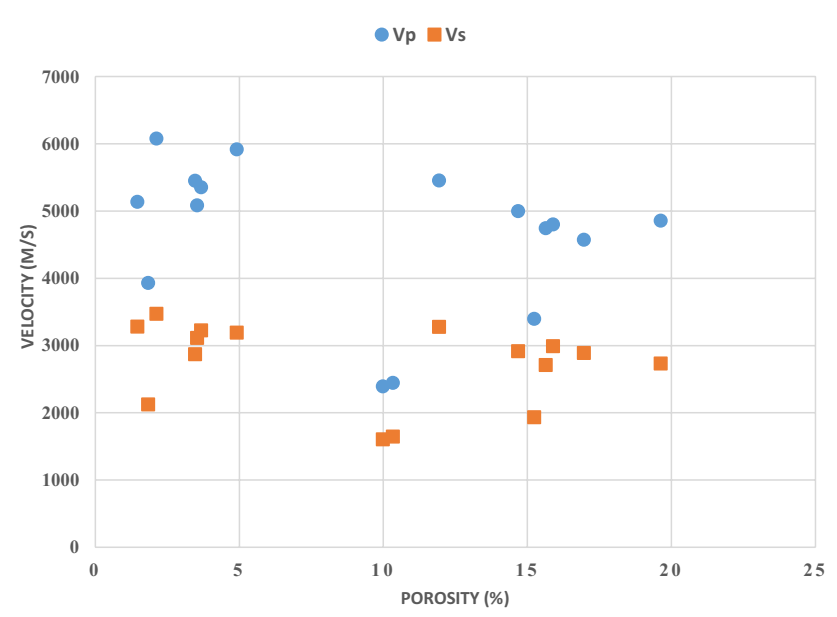

Fig. 4 Acoustic velocities relations with porosity under dry conditions and with no application of stresses

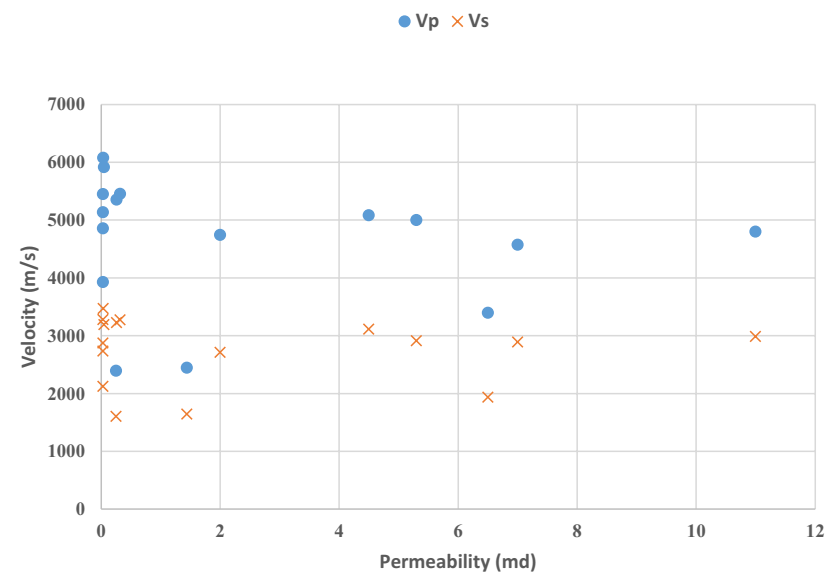

Fig. 5 Acoustic velocities trends with permeability under dry conditions and with no application of stresses

\subsection{Acoustic velocity relation with porosity, permeability and density}

In the conducted tests under dry conditions and with no applied stresses, it was observed that as the porosity and permeability increase, the acoustic velocity decreases. This is illustrated in Figs. 4 and 5. Furthermore, it has been found that the acoustic velocity has an inverse relation with rock density. In addition, we have noted that the samples with same porosities can have compressional velocity differences over $2000 \mathrm{~m} / \mathrm{s}$ and almost $1300 \mathrm{~m} / \mathrm{s}$ in shear velocity. These observations are consistent with previous studies in the literature and can be related to the presence of different pore types in the carbonate rocks $[5,30]$.

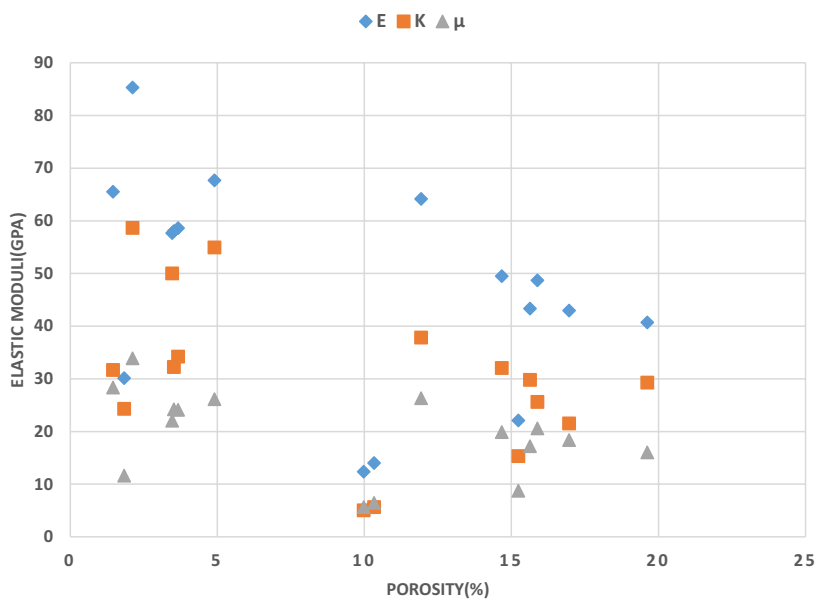

Fig. 6 The variation elastic modulus values with porosity

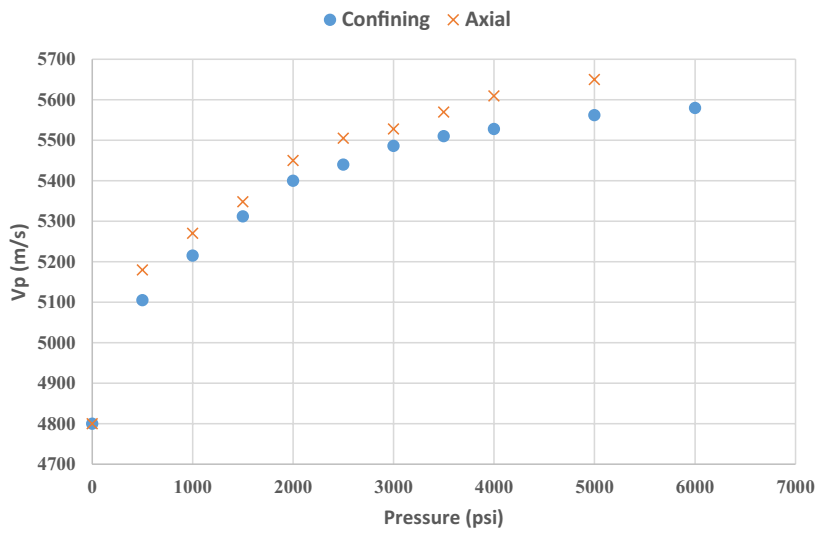

Fig. 7 The effect of axial and confining stresses on $\mathrm{Vp}$

\subsection{Elastic modulus and porosity relations}

For each tested sample, the magnitudes of the Young's modulus, shear modulus and bulk modulus were determined using the Eqs. (3-7). Figure 6 illustrates the change in elastic modulus values with porosity. It was observed that as the porosity increases, all the three elastic parameters decreases. Also, in all the test samples, the Young's modulus values were greater than the shear modulus and bulk modulus.

\subsection{Axial and confining stress effect on acoustic velocity}

To investigate the stress effect, we have selected two samples, that is, A10 and A16, which have the highest and lowest porosity values respectively. For the porous sample A10, the stress effects are shown in Figs. 7 and 8. In Fig. 7, one of the axial and confining stresses are kept constant at 


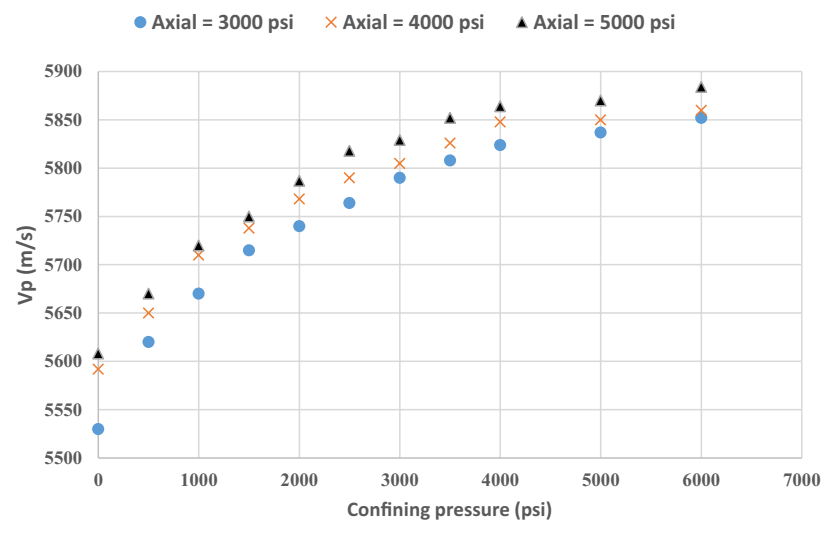

Fig. 8 The interaction effect of the axial and confining stresses on $\mathrm{Vp}$

atmospheric pressure while the other one was increased with a measurement for the compressional velocity. Generally, as the stresses increases, the compressional velocity increases. In this regard, the axial stress has a more pronounced effect on the compressional velocity than the confining stress. This can be related to the fact that the applied axial stress is parallel to wave propagation direction and at this direction we have most sensitive velocity [24].

In addition, for three constant axial stress levels of 3000 , 4000 and $5000 \mathrm{psi}$, the confining pressure was varied up to 6000 psi with the measurement of the compressional velocity (see Fig. 8). as expected, with increasing the axial stress, the compressional velocity increased. Under the applied high axial stresses, all pores and fractures were closed and the effect of confining stress was minor. For the tight sample A16, the same results of the porous sample were obtained, however, the total velocity increasing was much smaller than that for the porous sample.

For all the available samples, it has been observed that the axial stress effect on compressional velocity is more than the confining stress. The differential compressional velocity of axial and confining stresses for the studied samples are shown in Fig. 9. In high porosity samples, this differential velocity is relatively high and observed to take a value more than $80 \mathrm{~m} / \mathrm{s}$ (Fig. 10).

\subsection{Fluid substitution effect on acoustic velocity and elastic moduli}

Two types of porous fluid were tested under different axial and confining stresses. Figures 11 and 12 show the compressional and shear velocity under dry and wet conditions for an effective axial stress and an effective confining stress of 3500 and 4500 psi respectively. It should be noted that at both dry and wet conditions the axial and confining

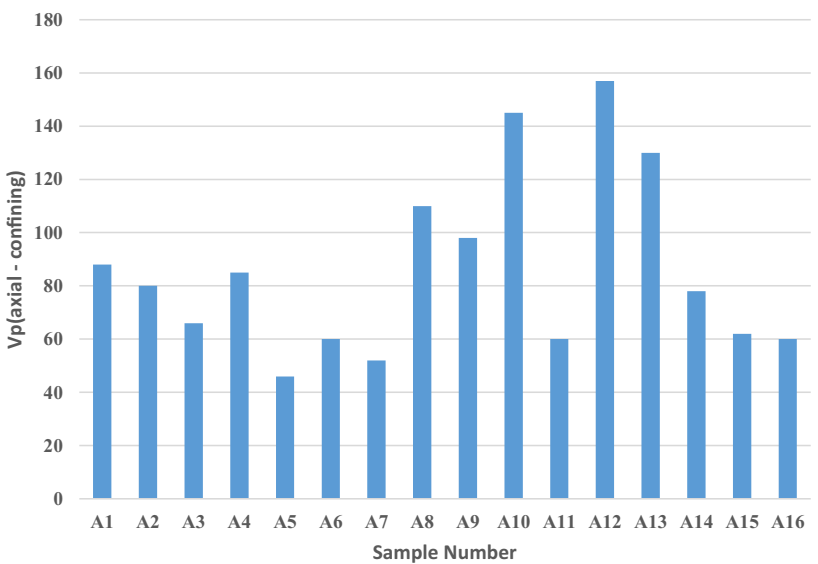

Fig. 9 Pressure effect on compressional velocity

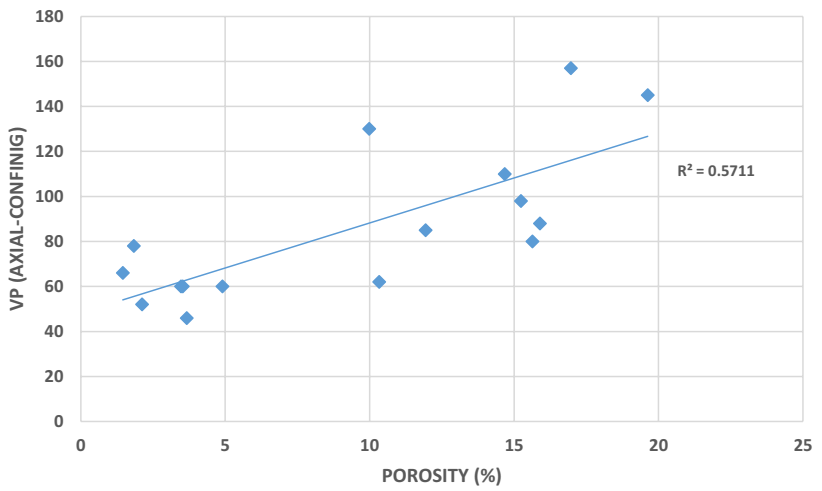

Fig. 10 Relation of differential compressional velocity and porosity

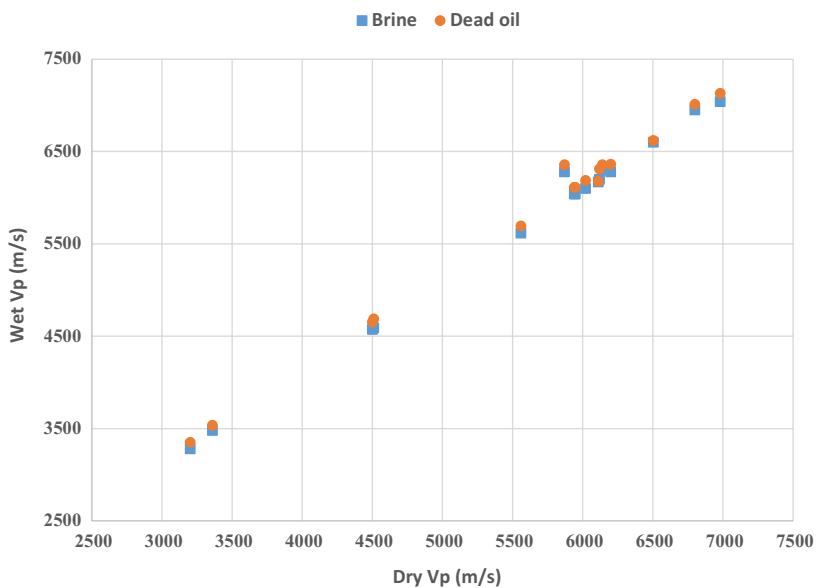

Fig. 11 Comparison of Vp in dry and wet conditions

stresses were 5000 and 6000 psi respectively. In addition, for the wet condition, the pore pressure is kept constant at 1500 psi. At such applied high stresses, all pores and micro cracks are expected to be closed and the velocity 


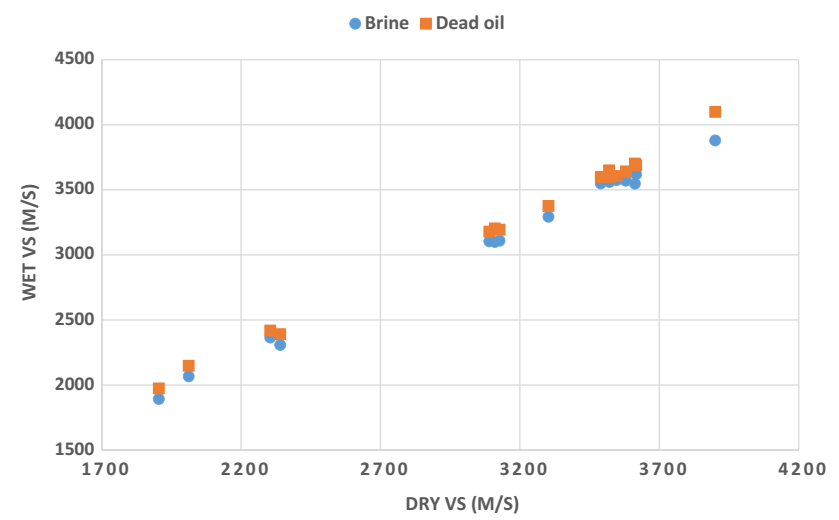

Fig. 12 Comparison of Vs in dry and wet conditions

dispersion mechanisms effect are minimum. Accordingly, the two acoustic velocities for the dry and wet conditions are nearly equal $[22,33]$. Due to the high viscosity of deal oil and the existence of high frequency, viscous coupling mechanism and velocity dispersion are more active. In this case, the compressional velocities of dead oil saturated samples are higher than ones for brine saturated samples. Furthermore, the shear velocity of brine saturated samples are lower than dead oil saturated ones.

To fully understand why these changes are observed in acoustic velocity and particularly in shear velocity, we measured the wettability of all samples. Wettability is the tendency of one fluid to adhere the surface in the presence of another fluid. Among many methods for measuring wettability, we used the most common quantitative method, that is, contact angle method [4]. Four samples with strong water wetting (i.e., $A 1, A 9, A 12$ and $A 13$ ) and three samples with oil wetting (i.e., $A 3, A 5$ and $A 7$ ) were studied. It has been observed that in high water wet samples, the water quickly spreads on the surface. In addition, we have noticed that when saturating these samples with brine the shear velocity decreased, while for dead oil the shear velocity increased specially in tight samples.

In tight samples where porosity and permeability are low, pore spaces are small and surface areas are high, capillary pressure pushes the wetting phase to the pore space. This breaks solid-solid bonding which results in rock weakening [20]. Saturated oil samples with contact angles higher than $90^{\circ}$ are considered oil wet. In such samples, the capillary pressure moves the fluid into the smallest pores which have the highest surface area and causes rock weakening. This results in shear velocity and shear modulus reduction. However, the high viscosity of dead oil has opposite effect on these parameters. To represent the changes after saturating the samples with two fluids, we have introduced a new index called a relative change of shear modulus which is defined by
Relative change of shear modulus $(R C S)=\frac{\mu_{\text {Dead oil }}-\mu_{\text {Dry }}}{\mu_{\text {Brine }}-\mu_{\text {Dry }}}$.

Figure 13 illustrates the relative change of shear modulus for all the studied samples. It has been found that four samples having the highest RCS are, at the same time, strongly water wet. These samples are marked in blue circles in Fig. 13. The RCS value for sample A13 is almost 11, and this high magnitude of RCS can be attributed to the very low permeability of the sample $[14,31]$. For dead oil saturated samples, the RCS values are the lowest and represented by black triangles in Fig. 13. Furthermore, when the samples A3, A5 and A7 saturated with brine, they showed high shear velocities.

Figure 14 shows the bulk modulus of samples in dry and wet conditions under an axial stress of 3500 psi and a confining stress of $4500 \mathrm{psi}$. All the studied samples revealed an increase in bulk modulus after saturation with dead oil and brine. We have found that the bulk modulus of dead

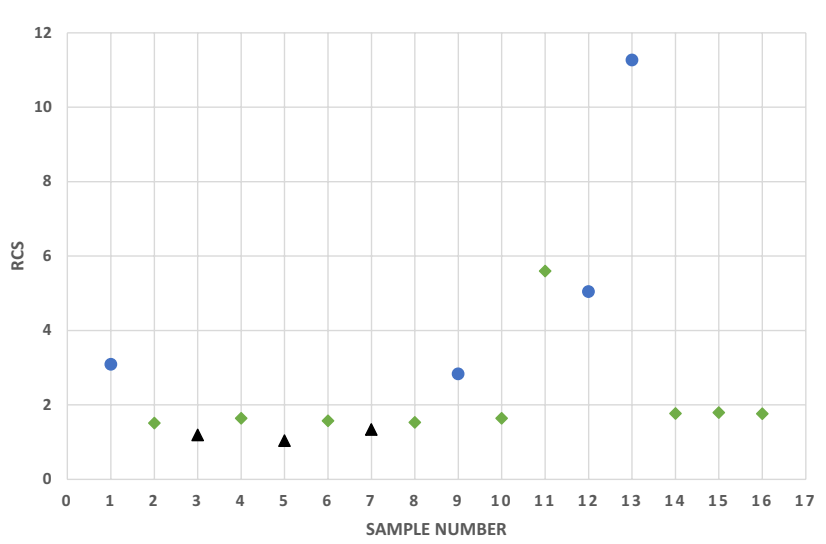

Fig. 13 RCS magnitudes for the studied samples

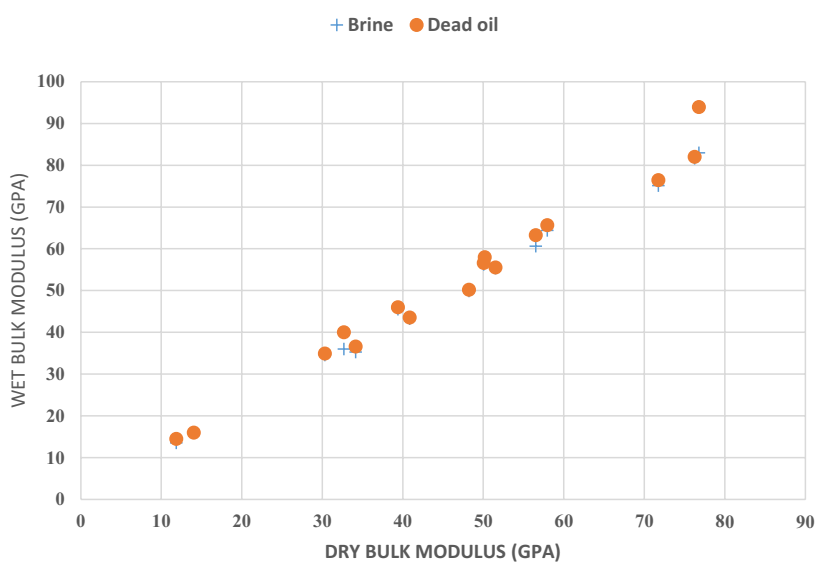

Fig. 14 Comparison of bulk modulus in dry and wet conditions 
oil saturated samples is relatively higher than brine saturated ones. This is due to the compressional velocities of dead oil saturated samples which are higher than those for brine saturated samples.

\section{Conclusions}

In addition to the confining stresses, the axial stresses were applied to 16 carbonate samples with different properties. It has been found that the axial stress effect on rock properties is greater than the effect of the confining stress which acts parallel to the wave propagation direction. For porous samples, the differential compressional velocity between the applied axial and confining stresses was the maximum over the studied samples. Among different mechanisms that influence acoustic velocity and elastic moduli, wettability effects are also investigated and highlighted, where wettability shows the effect of the velocity changes is due to the pore fluid type.

We have pointed out that the changes after saturating samples with two fluids can be expressed by the newly developed relative change of shear modulus index. For tight samples, we have observed that samples were more sensitive to fluid substitution than porous ones. The water wet samples strongly showed an increase in relative change of shear modulus while oil wet samples showed a reduction. However, for samples which have a contact angle greater than 0 and less than 80 , we have found no specific correlation with respect to the type of pore fluid applied. In general, the samples saturated with brine have less shear modulus than oil saturated samples due to the existence of high dead oil viscosity.

\section{Compliance with ethical standards}

Conflict of interest The authors declare that they have no conflict of interest.

\section{References}

1. Adam L, Batzle M, Brevik I (2006) Gassmann's fluid substitution and shear modulus variability in carbonates at laboratory seismic and ultrasonic frequencies. Geophysics 71:F173-F183

2. Aliyu MM, Shang J, Murphy W, Lawrence JA, Collier R, Kong F, Zhao Z (2019) Assessing the uniaxial compressive strength of extremely hard cryptocrystalline flint. Int J Rock Mech Min Sci 113:310-321

3. Ameen MS, Smart BG, Mc Somerville J, Hammilton S, Naji NA (2009) Predicting rock mechanical properties of carbonates from wireline logs (a case study: Arab-D reservoir, Ghawar field, Saudi Arabia). Mar Pet Geol 26:430-444

4. Anderson W (1986) Wettability literature survey-part 2: wettability measurement. J Pet Technol 38:1-246
5. Anselmetti FS, Eberli GP (1993) Controls on sonic velocity in carbonates. Pure Appl Geophys 141:287-323

6. Baechle GT, Eberli GP, Weger RJ, Massaferro JL (2009) Changes in dynamic shear moduli of carbonate rocks with fluid substitution. Geophysics 74:E135-E147

7. Baechle GT, Weger RJ, Eberli GP, Massaferro JL, Sun Y-F (2005) Changes of shear moduli in carbonate rocks: implications for Gassmann applicability. Lead Edge 24:507-510

8. Birch $F(1960)$ The velocity of compressional waves in rocks to 10 kilobars: 1. J Geophys Res 65:1083-1102

9. Brandås LT (2012) Relating acoustic wave velocities to formation mechanical properties

10. Brotons V, Tomás R, Ivorra S, Grediaga A, Martínez-Martínez J, Benavente D, Gómez-Heras M (2016) Improved correlation between the static and dynamic elastic modulus of different types of rocks. Mater Struct 49:3021-3037

11. Chan J, Schmitt DR (2015) Elastic anisotropy of a metamorphic rock sample of the Canadian Shield in Northeastern Alberta. Rock Mech Rock Eng 48:1369-1385

12. Chang C, Zoback MD, Khaksar A (2006) Empirical relations between rock strength and physical properties in sedimentary rocks. J Petrol Sci Eng 51:223-237

13. El-Husseiny A, Vega S, Nizamuddin S (2019) The effect of pore structure complexity and saturation history on the variations of acoustic velocity as function of brine and oil saturation in carbonates. J Petrol Sci Eng 179:180-191

14. Fabricius IL, Bächle GT, Eberli GP (2008) Water weakening of elastic moduli of carbonates interpreted by use of iso-frame modeling. In: 2008 SEG annual meeting. Society of Exploration Geophysicists

15. Fattahpour V, Moosavi M, Mehranpour M (2012) An experimental investigation on the effect of rock strength and perforation size on sand production. J Petrol Sci Eng 86:172-189

16. Fjær E (2019) Relations between static and dynamic moduli of sedimentary rocks. Geophys Prospect 67:128-139

17. Fortin J, Stanchits S, Dresen G, Guéguen Y (2006) Acoustic emission and velocities associated with the formation of compaction bands in sandstone. J Geophys Res Solid Earth. https ://doi.org/10.1029/2005JB003854

18. Fredrich JOANNET, Arguello JG, Deitrick GL, De Rouffignac EP (2000) Geomechanical modeling of reservoir compaction, surface subsidence, and casing damage at the Belridge diatomite field. SPE Reserv Eval Eng 3:348-359

19. Khaksar A, Griffiths CM, McCann C (1999) Compressional-and shear-wave velocities as a function of confining stress in dry sandstones. Geophys Prospect 47:487-508

20. Khazanehdari J, Sothcott J (2003) Variation in dynamic elastic shear modulus of sandstone upon fluid saturation and substitution. Geophysics 68:472-481

21. Martínez-Martínez J, Benavente D, García-del-Cura MA (2012) Comparison of the static and dynamic elastic modulus in carbonate rocks. Bull Eng Geol Environ 71:263-268

22. Mikhaltsevitch V, Lebedev M, Gurevich B (2016) Laboratory measurements of the effect of fluid saturation on elastic properties of carbonates at seismic frequencies. Geophys Prospect 64:799-809

23. Miller SLM (1992) Well log analysis of Vp and Vs in carbonates. CREWES research report

24. Mitra A, Engelder T, Aldin M, Govindarajan S (2016) Ultrasonic velocity measurement of sidewall cores for different stress paths. In: 50th US rock mechanics/geomechanics symposium. American Rock Mechanics Association

25. Najibi AR, Ghafoori M, Lashkaripour GR, Asef MR (2015) Empirical relations between strength and static and dynamic elastic properties of Asmari and Sarvak limestones, two main oil reservoirs in Iran. J Petrol Sci Eng 126:78-82 
26. Nauroy J-F (2011) Geomechanics applied to the petroleum industry. Editions Technip, Paris

27. Rafavich F, St CH, Kendall C, Todd TP (1984) The relationship between acoustic properties and the petrographic character of carbonate rocks. Geophysics 49:1622-1636

28. Røgen B, Fabricius IL, Japsen P, Høier C, Mavko G, Pedersen JM (2005) Ultrasonic velocities of North Sea chalk samples: influence of porosity, fluid content and texture. Geophys Prospect 53:481-496

29. Soete J, Kleipool LM, Claes H, Claes S, Hamaekers H, Kele S, Özkul M, Foubert A, Reijmer JJ, Swennen R (2015) Acoustic properties in travertines and their relation to porosity and pore types. Mar Pet Geol 59:320-335

30. Verwer K, Braaksma H, Kenter JA (2008) Acoustic properties of carbonates: effects of rock texture and implications for fluid substitution. Geophysics 73:B51-B65

31. Verwer K, Eberli G, Baechle G, Weger R (2010) Effect of carbonate pore structure on dynamic shear moduli. Geophysics 75:E1-E8

32. Wang Z, Schmitt DR, Wang R (2015) Does wettability influence seismic wave propagation in liquid-saturated porous rocks? Geophys J Int 203:2182-2188
33. Winkler KW (1985) Dispersion analysis of velocity and attenuation in Berea sandstone. J Geophys Res Solid Earth 90:6793-6800

34. Winkler KW (1986) Estimates of velocity dispersion between seismic and ultrasonic frequencies. Geophysics 51:183-189

35. Zoback MD (2010) Reservoir geomechanics. Cambridge University Press, Cambridge

36. Zoback MD, Barton CA, Brudy M, Castillo DA, Finkbeiner T, Grollimund BR, Moos DB, Peska P, Ward CD, Wiprut DJ (2003) Determination of stress orientation and magnitude in deep wells. Int J Rock Mech Min Sci 40:1049-1076

Publisher's Note Springer Nature remains neutral with regard to jurisdictional claims in published maps and institutional affiliations. 